\title{
A Comparative Study on the Microbial Communities of Rhynchophorus ferrugineus (Red Palm Weevil)-Infected and Healthy Palm Trees
}

\author{
N. Alshammari ${ }^{1}$ (]) Meshari Alazmi ${ }^{2} \cdot$ Naimah A. Alanazi $^{1} \cdot$ Abdel Moneim E. Sulieman $^{1} \cdot$ Vajid N. Veettil $^{1,3} \cdot$ \\ Manuel Ponce-Alonso ${ }^{4}$
}

Received: 23 February 2021 / Accepted: 5 July 2021 / Published online: 25 August 2021

(c) The Author(s) 2021

\begin{abstract}
Several studies have investigated palm trees' microbiota infected with red palm weevil (RPW) (Rhynchophorus ferrugineus), the major pest of palm trees. This study compared the microbial communities of infected and uninfected palm trees in the Hail region, Northern Saudi Arabia, determined by high-throughput 16S rRNA gene sequencing by Illumina MiSeq. The results indicated that taxonomic diversity variation was higher for infected tree trunk than the healthy tree trunk. Soil samples from the vicinity of healthy and infected trees did not have a significant variation in bacterial diversity. Myxococcota, Acidobacteriota, and Firmicutes were the dominant phyla in RPW-infected tree trunk, and Pseudomonadaceae was the most prominent family. This study is the first report on the characterization of RPW-infected and healthy palm trees' microbiome.
\end{abstract}

Keywords Rhynchophorus ferrugineus $\cdot$ Red palm weevil $\cdot$ Microbial community $\cdot$ Palm tree $\cdot$ Illumina MiSeq $\cdot$ Hail region · Northern Saudi Arabia

N. Alshammari

naib.alshammari@uoh.edu.sa

Meshari Alazmi

ms.alazmi@uoh.edu.sa

Naimah A. Alanazi

n.alenezy@uoh.edu.sa

Abdel Moneim E. Sulieman

am.sulieman@uoh.edu.sa

Vajid N. Veettil

vajidnv@gmail.com

Manuel Ponce-Alonso

lugonauta@gmail.com

1 Department of Biology, College of Sciences, University of Ha'il, P.O. Box 2440, Hail 81411, Saudi Arabia

2 Department of Information and Computer Science, College of Computer Science and Engineering, University of Ha'il, P.O. Box 2440, Hail 81411, Saudi Arabia

3 Research Scholar, Department of Microbiology, Sree Narayana Guru College, Coimbatore, India

4 Servicio de Microbiología, Instituto Ramón Y Cajal de Investigación Sanitaria (IRYCIS), Hospital Universitario Ramón Y Cajal, Carretera de Colmenar, Km 9.1, 28034 Madrid, Spain

\section{Introduction}

Date palm tree (Phoenix dactylifera L.) holds a significant cultural and economic status in many Middle East regions since ancient times. The Kingdom of Saudi Arabia is among the top three date-producing countries globally, with date production amounting to 1.3 million tonnes, accounting for nearly $17 \%$ of the global date production. Consequently, it is also the world leader in the cultivation of palm trees, and currently, there are around 28.5 million palm trees in the country. However, infections by several insect pests, fungal and bacterial pathogens and other pathogenic agents, nematode diseases, birds, weeds, and succession by other species are the critical issues in palm tree cultivation, which directly affects date production.

The red palm weevil (RPW) Rhynchophorus ferrugineus Olivier (Coleoptera: Curculionidae), an invasive woodboring insect, is the most dangerous and destructive pest to date palm trees and ornamental palm trees in this region [1]. This insect has been designated as a Category 1 date palm pest in the Middle East by the United Nations Food and Agriculture Organization [2] and is often referred to as the 'cancer' of palm trees. RPW is a native of South East Asia, but foreign trade of contaminated plant parts over the last two decades has facilitated its spread and infestation in 
the Middle East [3]. Rhynchophorus ferrugineus infects the palm tree by injuring the apical regions, armpit palms, or digging gallery. Infection is established by the presence of necrosis, oozing of a brown viscous liquid, or the presence of perforation on the surface of the trunk. When infection is more advanced, there is a collapse and a sudden drying of palms and abnormal umbrella-shaped canopy is noticed. Heavily infected trees show loss of all their palms and rotting of the trunk, and this is often followed by death of the palm tree. Due to the impact of RPW, hundreds of thousands of infested palm trees die each year [4], resulting in substantial ecological, environmental, and economic losses.

Considering the economic and social effects of RPW infestations, the focus on control and eradication of this pest has significantly increased in the last decades. Evaluating the efficacy of various chemical and bio-control methods has been the theme of most research work in this field [5, 6]. Compared to unrestricted pesticide use, biological control involving the biological system administration is more effective and environmental friendly [7, 8]. In this aspect, the microbial profile of PRW has not been adequately understood, although an intracellular endosymbiont, 'Candidatusnardonella' has been identified in RPW $[9,10]$. Several studies have been carried out to characterize gut bacterial population in RPW [11, 12]. Other studies aimed at identifying possible bacterial pathogens in RPW to develop biocontrol strategies against this insect [13, 14]. Studies by $\mathrm{Pu}$ et al. have shown that Bacillus thuringiensis $(\mathrm{Bt})$ can be used as a potential bio-pesticide for RPW control and can effectively minimize damage to palm trees [15]. In another study form our own institutes, we found that the genera Aspergillus and Fusarium spp were highly associated with RPW [16]. Another study found that different types of bacilli were associated with RPW [17].
Another strategy for eradicating pathogenic infections in plants is by controlling phytoplasmas, which are pathogenic bacteria inhabiting plants and transmitted by insect vectors such as Hemiptera [18]. Although removal of infected plant that serves as source inoculum helps mitigate disease to some extent [19, 20], efficient control has not been found to date. Understanding an infected plant's microbial community profile compared with an uninfected and healthy plant's microbial profile will help develop an effective bio-control strategy or find out new bacteria. There have been no reports on microbial communities of the date palm tree, diseased or healthy. This study was carried out to examine the contrast of microbial communities among RPW-infected palm trees and healthy trees as a primary data source for forthcoming comprehensive studies. To date, there are no reports on microbiome analysis of palm trees and the effect of RPW infestation on the host-microbial community.

\section{Materials and Methods}

\subsection{Study Site}

The study site is located in the Hail region of Northern Saudi Arabia ( $\left(27^{\circ} 59^{\prime} 05.7^{\prime \prime} \mathrm{N}\right.$ and $41^{\circ} 45^{\prime} 46.3^{\prime \prime}$ E). Climate is hot in summers and cold in winters, with the temperature ranging from 34 to $44{ }^{\circ} \mathrm{C}$ in the summer and $2-16{ }^{\circ} \mathrm{C}$ in winters. Average annual precipitation ranges from 10 to $20 \mathrm{~cm}$, and the site is vulnerable to extreme conditions like storms and droughts. Several species of palm trees dominate the flora of this region as shown in Fig. 1.
Fig. 1 a Red palm weevil documented on palm tree trunk, b infected tree trunk, $\mathbf{c}$ healthy tree trunk

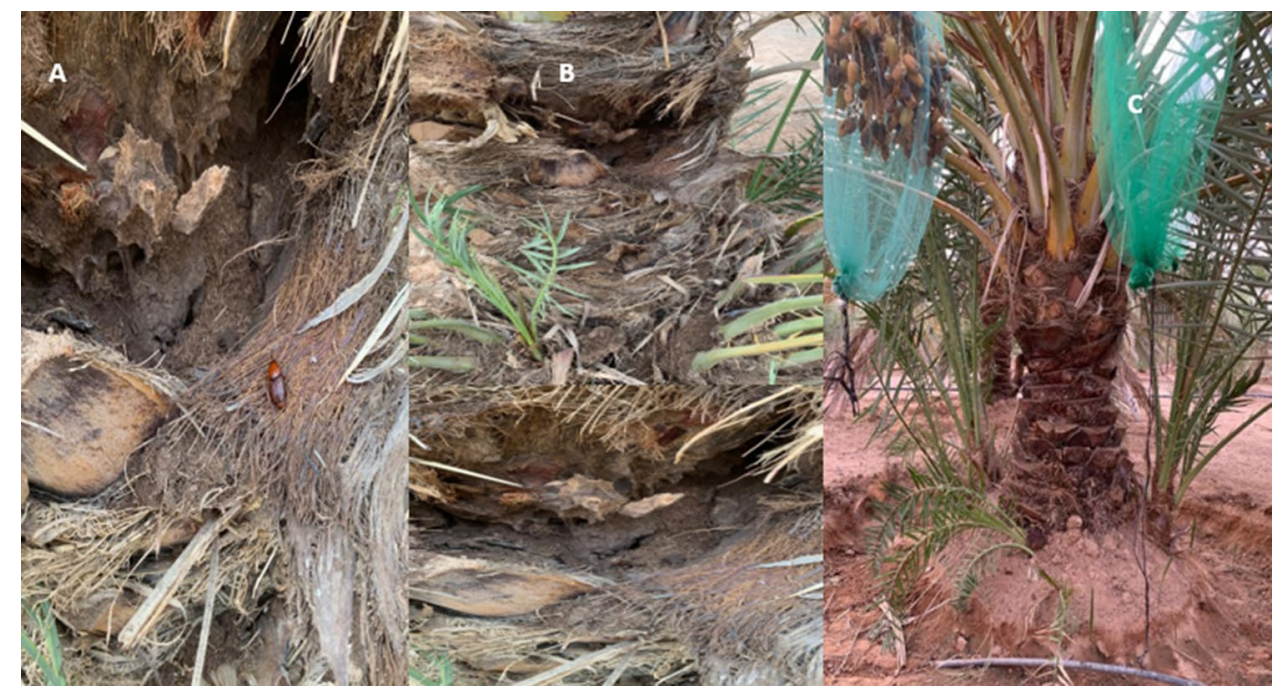




\subsection{Sample Collection}

Sampling was carried out at the study site during September 2020, when RPW disease infestations were observed in the palm trees. Samples were collected from infected tree which contain numerous egg and larvae. Presences of more than 50 adult pest in and around the tree were observed. All infected palm tree had multiple perforations which could count for more than five. Trunks destroyed from the middle could reasonably be assumed to be created by RPW. Uninfected or healthy trees were selected by observing plants with no trunk perforations and absence of egg and larvae of the insect. Both infected and healthy tree samples were taken from the trunk tissue. The trees were photographed in the field, followed by the removal of the trunk from the base. Trunk samples (measuring $1 \mathrm{~cm}$ in diameter and $5 \mathrm{~cm}$ in length) were cut by a sterile knife, further sized down to $0.5 \mathrm{~cm}$ in thickness and $0.8 \mathrm{~cm}$ in diameter, placed in an Eppendorf tube and stored in liquid nitrogen for transport. Additionally, samples of soil close to the trees' base were collected using a knife or a small hatchet after removing debris and litter from the surface. Samples were then placed in a plastic collecting box labeled with a unique number and returned to the laboratory. Totally 12 samples were collected. Three samples were obtained from the trunk and soil each of a palm tree that had never been infected by RPW, whereas the other three samples were collected from the trunk and soil of RPW-infected palm.

\subsection{DNA Extraction, PCR, and 16S rRNA Sequencing}

DNA was isolated from one or more representative trunk for each different palm tree, tentatively identified based on RPW infections, using an EZNA HP Plant DNA Kit (Omega). Genomic DNA was amplified using 1541R 5' AAGGGG TGATCCAGCCAGCCCA-3' and 8F 5' AGAGTTTGATCC TGGCTCAG-3' primers [18, 21]. The $16 \mathrm{~S}$ ribosomal RNA gene was amplified using polymerase chain reaction (PCR) (at $95{ }^{\circ} \mathrm{C}$ for $3 \mathrm{~min}$, followed by 35 cycles at $98^{\circ} \mathrm{C}$ for $30 \mathrm{~s}$, then for $30 \mathrm{~s}$ at $55^{\circ} \mathrm{C}, 72{ }^{\circ} \mathrm{C}$ for $1 \mathrm{~min}$, and at the end of the extension for $5 \mathrm{~min}$ at $72{ }^{\circ} \mathrm{C}$ ). PCRs were carried out in a $25-\mu \mathrm{l}$ mixture containing $1 \mu \mathrm{l}$ of each universal primer $(8 \mathrm{~F}$ and 1541R); $3 \mu \mathrm{l}$ of DNA template; $7.5 \mu \mathrm{l}$ of nuclease-free water and $12.5 \mu$ of GoTaq ${ }^{\circledR}$ Green Master Mix (Promega ${ }^{\text {TM }}$ Corporation, WI). Agarose gel electrophoresis was carried out using $1 \mu \mathrm{l}$ of SYBR Safe DNA Gel Stain (Thermo Fisher Scientific) fluorescent dye; assess the amplification of the 16S rRNA region.

\subsection{Preparation of 16S rRNA Amplicon Libraries and Illumina MiSeq Sequencing}

By targeting the V4 region of the bacterial 16S rRNA gene, Index PCR was carried out by the dual-index strategy for primer design as described in an earlier study [19, 20, 22]. In short, dual-index PCR reaction was carried out in $25-\mu \mathrm{l}$ reaction mixture consisting of $3 \mu \mathrm{l}$ of DNA template, $2.5 \mu \mathrm{l}$ of AccuPrime ${ }^{\mathrm{TM}}$ PCR buffer II, $0.5 \mu \mathrm{l}$ of individually index primers, $0.1 \mu$ of AccuPrime ${ }^{\mathrm{TM}}$ Taq DNA Polymerase (Invitrogen, Carlsbad, CA), and $18.4 \mu \mathrm{l}$ of nuclease-free water according to the manufacture's protocol. PCR amplifications were performed with an initial denaturation for $3 \mathrm{~min}$ at $95{ }^{\circ} \mathrm{C}$. Temperature cycling at $95{ }^{\circ} \mathrm{C}$ for $30 \mathrm{~s}$ and $55^{\circ} \mathrm{C}$ for $30 \mathrm{~s}$ primer annealing, and extension at $72^{\circ} \mathrm{C}$ for one minute for 35 cycles. Using SequalPrep kits (Invitrogen), the exact size amplicons were conducted according to the manufacturer's procedure to purify and normalize subsequent positive magnification. After pooling the library, the concentrations of amplicons were calculated using an Agilent bioanalyzer.

The amplicon library was counted through qPCR using the same primers and PerfeCta NGS library quantification kits (Quanta Biosciences Inc., Beverly, MA, United States) for actual exact concentration, according to the manufacturer's directions. During counting, the library was denatured, diluted, and sequenced on an Illumina MiSeq to suitable concentrations. Sequencing reads were downloaded in Fastq file format from the Illumina Basespace server. At read 1, the sequences were demultiplexed, and read 2 was obtained with a length of approximately $250 \mathrm{bp}$. Practical taxonomic parts were defined and classified by $95 \%$ matching with a reference in the SILVA database. Further analysis was carried out using Mothur v1.41.1 Pipeline [22]. Nonmetric multidimensional scaling (NMDS) plots were acquired based on the Bray-Curtis index using PAST 3.18 software [23]. Statistical analysis was carried out using standard methods and LEfSE based on Linear Discriminant Analysis (LDA).

\subsection{Statistics}

Data analysis was done using R software environment for statistical computing and graphics version 4.0.3 (R Core Team, 2021). Categorical data were represented by frequency and percentage, and non-normal continuous data were represented using median [1st Quartile, 3rd Quartile]. A comparison between the groups was made using the Kruskal-Wallis test and Pairwise Wilcoxon Rank Sum Test (PWRST). $p<0.05$ was considered significant.

\section{Results}

\subsection{Diversity of Microbial Population between Diseased and Healthy PaIm Trees}

In the study area, five plants were infected among 300 plants. The infections were very typical of RPW with plant foliar damage as well as the trunk contain numerous egg 
and larva. These resulted in observable tissue damage and fermentation of trunk area of the plant. Red palm weevil is a hidden pest most of its life cycle developing inside the palm tree except the adult which is coming out of the tree rarely.

A total of 1620 bacterial amplicon sequence variants (ASV) were obtained (median value) from soil and trunk of healthy and infected palm trees. Using the Kruskal-Wallis test, it was found statistical significance on the diversity between the family, genus and phylum of microbial community of soil samples and trunk samples of healthy and diseased palm trees as evident from comparison of median values ( $p<0.05$ for all pairs) (Table 1$)$. However, no significant differences were observed between the family, genus or phylum of healthy and diseased samples of soil or tree trunk as analyzed by unpaired Wilcoxon test (Table 2). Tree trunk samples had more diversity and richness of microbial community as compared to soil samples. Besides, no significant differences in diversity in the microbial community in the soil samples collected from around healthy trees and the soil from infected trees were observed. In contrast, the highest community richness and diversity were observed in diseased tree trunk samples compared to the healthy tree trunk (Fig. 2).

\subsection{Bacterial Community Structure at Taxonomic Levels between Diseased and Healthy Palm Trees}

Illumina MiSeq was used to characterize bacterial strains into at various taxonomic level viz. phylum, families and genus. A comparison between microbial community of healthy and RPW-infected palm tree trunk was then drawn to elucidate the community structure at various taxonomic levels.

Table 3 shows the different phylum found in the healthy and infected palm tree trunk. It was observed that trunk samples collected from infected palm tree had maximum bacterial diversity represented by 27 different phyla. Of the 27 different phyla, 10 phyla were dominant with more than 5000 ASVs. On the other hand, uninfected palm tree trunk presented 20 different phylum levels with only seven dominant phyla repeated more than 5,000 times. Also, Proteobacteria and Bacteroidota were the dominant phyla with the highest representation in both healthy and infected trunk samples (Fig. 3). Additionally, phyla Myxococcota, Acidobacteriota, and Firmicutes were found exclusively in the sample from the infected trunk and were absent in healthy tree samples.

At the family level, 480 different families were identified in both healthy and infected trunk samples. In samples from RPW-infected trees, diversity at the family level

Table 1 Diversity of microbial population between diseased and healthy palm trees was compared by Kruskal-Wallis test

\begin{tabular}{|c|c|c|c|c|c|}
\hline \multirow[t]{2}{*}{ Factor } & & \multicolumn{4}{|l|}{ Taxonomic level } \\
\hline & & Family & Genus & Phylum & $p$-Value \\
\hline \multirow[t]{2}{*}{ Soil } & $N$ & 318 & 519 & 32 & $<0.0001$ \\
\hline & Median [Q1, Q3] & $36.83[8.67,224.92]$ & $25.33[6.67,124.83]$ & $177.5[31.92,2088.83]$ & \\
\hline \multirow[t]{2}{*}{ Infected soil } & $N$ & 380 & 716 & 32 & $<0.0001$ \\
\hline & Median [Q1, Q3] & $42.17[8.58,228.42]$ & $25.17[6.33,101.42]$ & $145[21.83,2014.67]$ & \\
\hline \multirow[t]{2}{*}{ Trunk } & $n$ & 218 & 366 & 21 & 0.0006 \\
\hline & Median [Q1, Q3] & $55.5[8,227.5]$ & $31.17[6.75,183.33]$ & $809.33[31.33,2443]$ & \\
\hline \multirow[t]{2}{*}{ Infected trunk } & $n$ & 328 & 553 & 28 & $<0.0001$ \\
\hline & Median [Q1, Q3] & $41[11.25,191.33]$ & $20.67[6,100]$ & $210.67[14.67,3467.83]$ & \\
\hline
\end{tabular}

$n$ Number of sequences; $p<0.05$ is considered significant

Table 2 Distribution of sequences at various taxonomic levels was compared by Wilcoxon test

\begin{tabular}{lllllll}
\hline Taxonomic level & Soil & Infected soil & $p$-Value & Trunk & Infected trunk & $p$-Value \\
\hline Family & $n$ & 318 & 380 & 0.94 & 218 & 328 \\
& Median [Q1, Q3] & $36.83[8.67,224.92]$ & $42.17[8.58,228.42]$ & & $55.5[8,227.5]$ & $41[11.25,191.33]$ \\
Genus & $n$ & 519 & 716 & 0.55 & 366 & 553 \\
& Median [Q1, Q3] & $25.33[6.67,124.83]$ & $25.17[6.33,101.42]$ & & $31.17[6.75,183.33]$ & $20.67[6,100]$ \\
Phylum & $n$ & 32 & 32 & 0.75 & 21 & 28 \\
& Median [Q1, Q3] & $177.5[31.92,2088.83]$ & $145[21.83,2014.67]$ & & $809.33[31.33,2443]$ & $210.67[14.67,3467.83]$ \\
\hline
\end{tabular}

$p<0.05$ is considered significant 


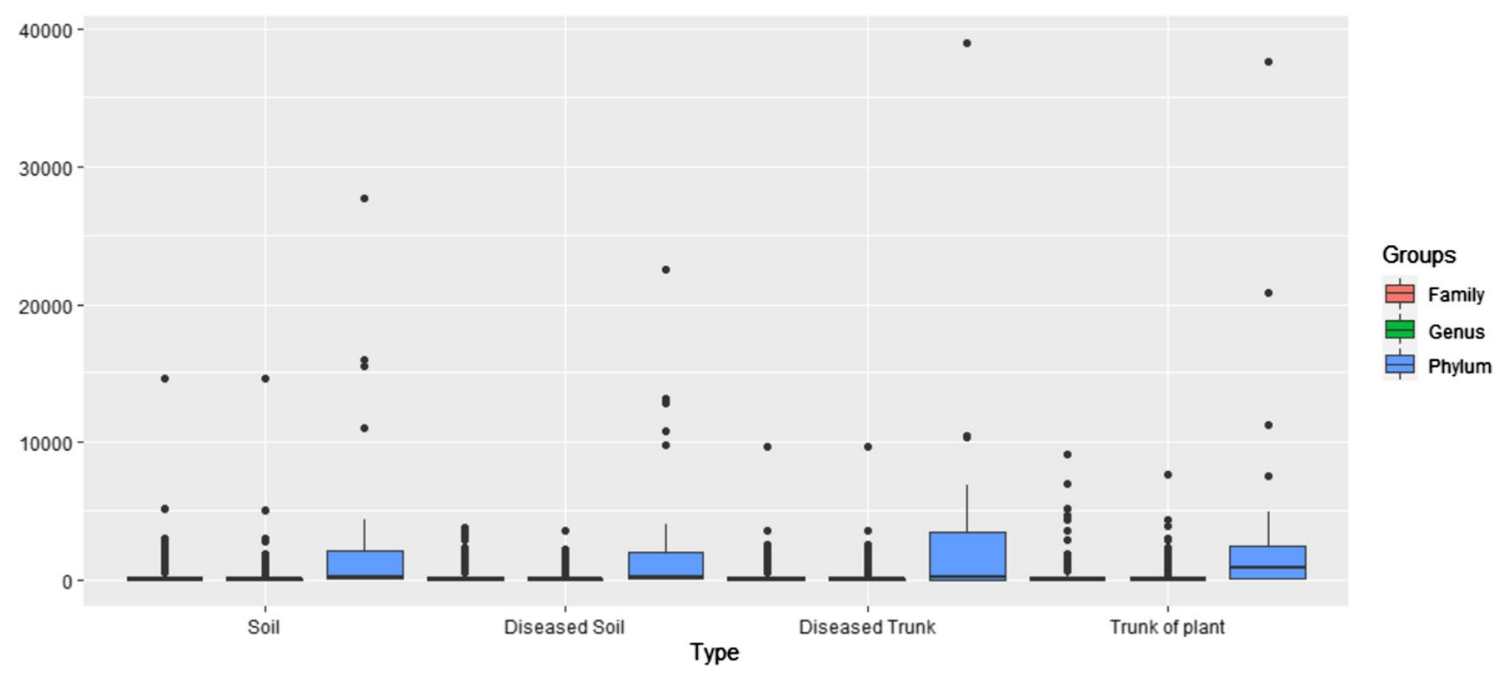

Fig. 2 Diversity of microbial population between diseased and healthy palm trees

Table 3 Distribution of dominate bacterial phylum in relation to the infection trunk substrate and no infection palm tree trunk

\begin{tabular}{|c|c|c|c|c|}
\hline \multirow[t]{2}{*}{ ASVID } & \multicolumn{2}{|c|}{ Healthy trunk $(\mathrm{CT})$} & \multicolumn{2}{|c|}{ Infected trunk (IT) } \\
\hline & No. of ASVs & $\%$ Distribution & No. of ASVs & $\%$ Distribution \\
\hline Myxococcota & 0 & 0 & 5489 & 2 \\
\hline Verrucomicrobiota & 14,582 & 5.6 & 6816 & 2 \\
\hline Acidobacteriota & 0 & 0 & 9593 & 3 \\
\hline Planctomycetota & 7330 & 2.8 & 12,835 & 5 \\
\hline Firmicutes & 0 & 0 & 13,288 & 5 \\
\hline Chloroflexi & 5677 & 2.19 & 18,026 & 7 \\
\hline Patescibacteria & 22,424 & 8.6 & 20,352 & 7 \\
\hline Actinobacteriota & 33,571 & 13 & 30,958 & 12 \\
\hline Bacteroidota & 62,492 & 24 & 31,235 & 12 \\
\hline Proteobacteria & 112,643 & 43.5 & 116,780 & 45 \\
\hline Total & 258,719 & 100 & 256,372 & 100 \\
\hline
\end{tabular}

IT presented infected palm tree trunk, $C T$ presented uninfected palm tree trunk was represented by 328 different families. On the contrary, 217 different families were characterized in samples from healthy tree trunk samples. A total of 26 different families were recorded for their richness due to greater number (> 5000 times) (Fig. 4). Of the 26 diversity-rich families, 15 families were from the infected tree and 11 from healthy tree samples. The Pseudomonadaceae family found in infected tree trunk has the highest distribution $(20 \%)$ among the various recorded families in both infected and healthy tree samples (Table 4).

At the genus level, up to 554 different genera were identified in the microbiome of infected trunk and 367 genera in the microbiome of healthy trunk. The microbial community of infected trunk was dominated by Pseudomonadaceae (20\%) and Chitinophagaceae (7\%). On the other hand, Caedibacteraceae (10\%) and Intrasporangiaceae
(9\%) were the dominant families in uninfected tree trunk samples (Table 5; Fig. 5).

Overall observations in trunk and soil are shown in Figs. 6 and 7.

\section{Discussion}

Many researchers have established, directly or indirectly gut microflora of the RPW is responsible for the degradation of palm tree. Some researchers focused on the bacterial study and some are on fungi. From our department in a previous study fungi related with the RPW were studied; Aspergillus niger contributed to the highest number of fungal isolates among all species, followed by Aspergillus 


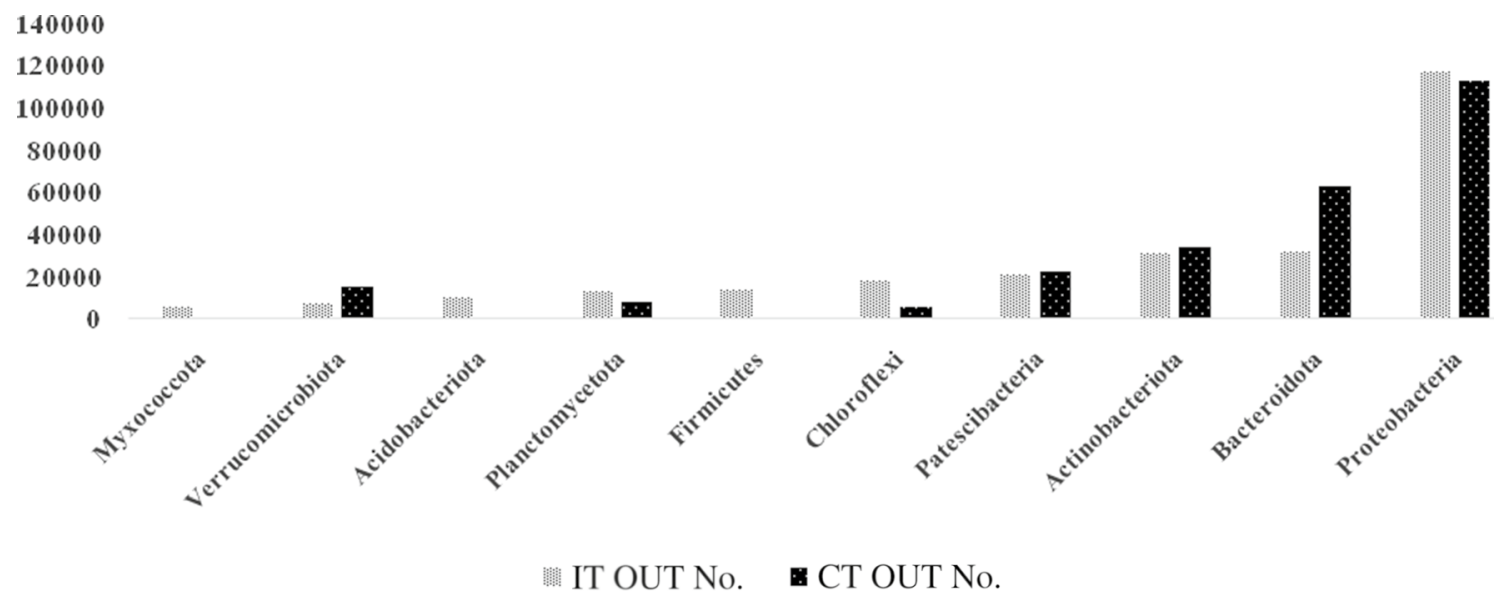

Fig. 3 Distribution and domains phyla in two different substrates (IT and CT)

Fig. 4 Distribution and dominant families in two different substrates (IT and CT)

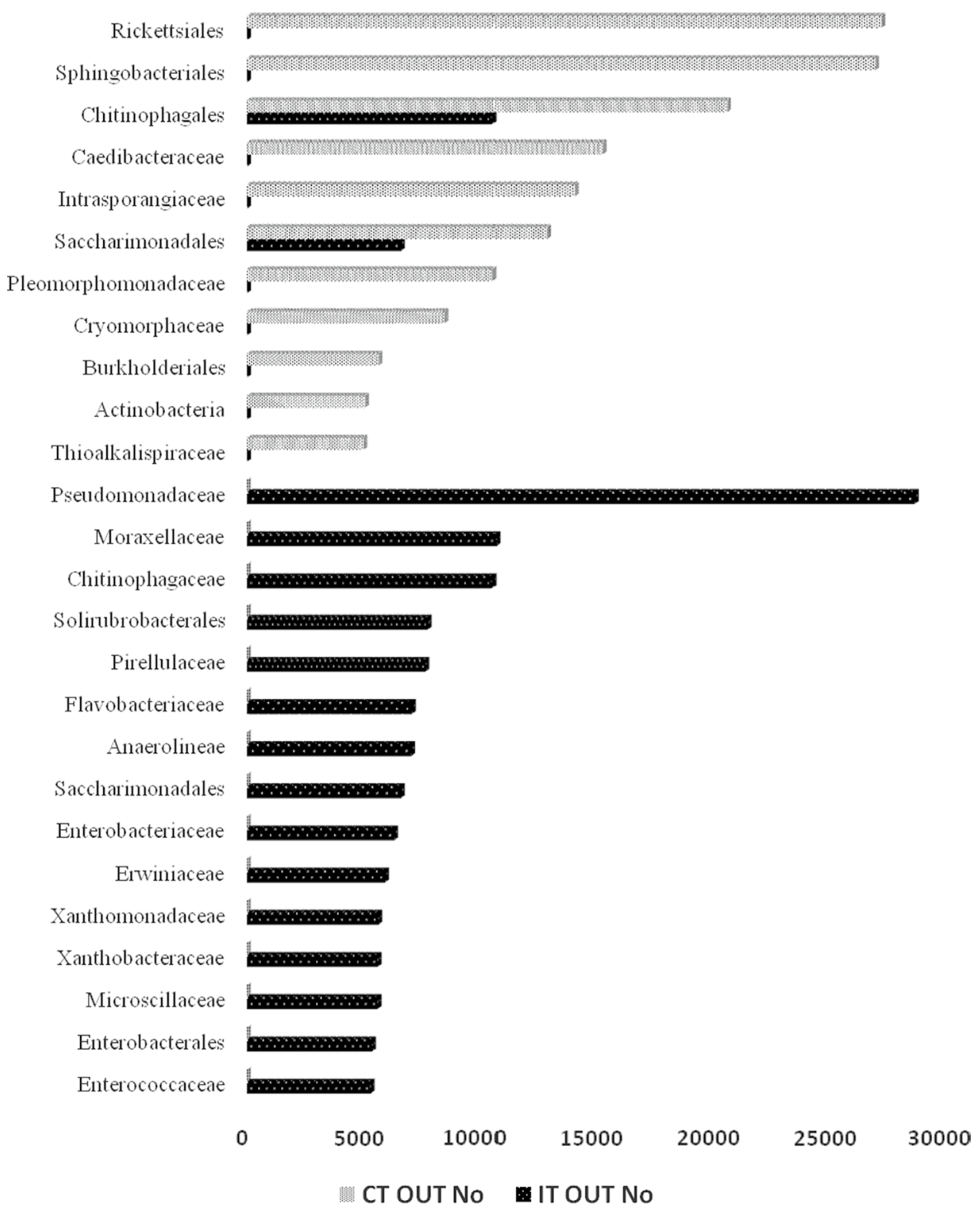


Table 4 Distribution of the dominant families presented in healthy trees $(\mathrm{CT})$ and infected trees (IT)

\begin{tabular}{|c|c|c|c|c|}
\hline ASVID & IT & \% Distribution & CT & \% Distribution \\
\hline Enterococcaceae & 5332 & 4 & 0 & 0 \\
\hline Enterobacterales & 5394 & 4 & 0 & 0 \\
\hline Microscillaceae & 5637 & 4 & 0 & 0 \\
\hline Xanthobacteraceae & 5639 & 4 & 0 & 0 \\
\hline Xanthomonadaceae & 5668 & 4 & 0 & 0 \\
\hline Erwiniaceae & 5954 & 4 & 0 & 0 \\
\hline Enterobacteriaceae & 6349 & 4 & 0 & 0 \\
\hline Saccharimonadales $\mid \mathrm{LWQ8}$ & 6635 & 5 & 0 & 0 \\
\hline AnaerolineaelSBR $1031 \mid \mathrm{A} 4 \mathrm{~b}$ & 7084 & 5 & 0 & 0 \\
\hline Flavobacteriaceae & 7114 & 5 & 0 & 0 \\
\hline Pirellulaceae & 7698 & 5 & 0 & 0 \\
\hline Solirubrobacterales|67-14 & 7797 & 5 & 0 & 0 \\
\hline Chitinophagaceae & 10,553 & 7 & 0 & 0 \\
\hline Moraxellaceae & 10,726 & 7 & 0 & 0 \\
\hline Pseudomonadaceae & 28,781 & 20 & 0 & 0 \\
\hline Thioalkalispiraceae & 0 & 0 & 5022 & 3 \\
\hline ActinobacterialPeM15|PeM15 & 0 & 0 & 5092 & 3 \\
\hline Burkholderiales|B1-7BS & 0 & 0 & 5679 & 4 \\
\hline Cryomorphaceae & 0 & 0 & 8522 & 6 \\
\hline Pleomorphomonadaceae & 0 & 0 & 10,552 & 7 \\
\hline Saccharimonadales $\mid \mathrm{S} 32$ & 6635 & 7 & 12,910 & 8 \\
\hline Intrasporangiaceae & 0 & 0 & 14,100 & 9 \\
\hline Caedibacteraceae & 0 & 0 & 15,307 & 10 \\
\hline Chitinophagales|37-13 & 10,553 & 7 & 20,673 & 14 \\
\hline Sphingobacteriales $\mid \mathrm{S} 15-21$ & 0 & 0 & 27,072 & 18 \\
\hline Rickettsiales $\mid \mathrm{SM} 2 \mathrm{D} 12$ & 0 & 0 & 27,338 & 18 \\
\hline Total & 143,549 & 100 & 152,267 & 100 \\
\hline
\end{tabular}

Table 5 Distribution of the dominant genera presented in both genera (IT and CT)

\begin{tabular}{lllll}
\hline ASVID & (IT) ASV & $\%$ & (CT) ASV & $\%$ \\
\hline Enterobacterales & 0 & 0 & 5022 & 5 \\
Rhizobiaceae & 5394 & 6.2 & 5835 & 6 \\
Segetibacter & 0 & 0 & 6387 & 7 \\
Gryllotalpicola & 0 & 0 & 6509 & 7 \\
Sphingomonas & 0 & 0 & 6862 & 7 \\
Flavobacterium & 6410 & 7 & 8521 & 9 \\
Asticcacaulis & 0 & 0 & 8935 & 9 \\
Sphingomonadaceae & 0 & 0 & 11,841 & 12.3 \\
Saccharimonadaceae|TM7a & 6635 & 8 & 12,910 & 13.4 \\
Mucilaginibacter & 0 & 0 & 22,924 & 23 \\
Enterococcus & 5332 & 6 & 0 & 0 \\
ChloroflexilAnaerolineae 1 & 7084 & 8 & 0 & 0 \\
Chitinophagales & 7562 & 9 & 0 & 0 \\
Solirubrobacterales & 7797 & 9 & 0 & 0 \\
Acinetobacter & 10,720 & 12.5 & 0 & 0 \\
Pseudomonas & 28,740 & 33.5 & 0 & 0 \\
Total & 85,674 & 100 & 95,746 & 100 \\
\hline
\end{tabular}

flavus and Fusarium solanum [16]. However, present study deals with bacterial isolates.

In that context, they could isolate many fermenting bacteria from the gut. In a study with germ free RPW larvae, it was proved that there is cross-talk between RPW and its gut microbiota [23]. RPW gut microbiota exhibited a highly stable microbial community with low variance in abundance across different life stages and host plants. In a study from Italy, they found many facultative and obligate anaerobic bacteria with a fermentative metabolism, mainly Dysgonomonas, Lactococcus, Salmonella, Enterobacter, Budvicia, Entomoplasma, Bacteroides and Comamona in RPW gut. These bacteria may be directly or indirectly responsible for the RPW larvae thrive [24, 25]. In the present study, efforts were made to isolate microorganism from the infected site and correlate between healthy plants.

In the present study, only two plants were included, the number of sample was low because while sampling requires to cut open the tree which causes huge economic loss to farmer as well as the study was aimed to have a pilot study by using next-generation sequencing. 


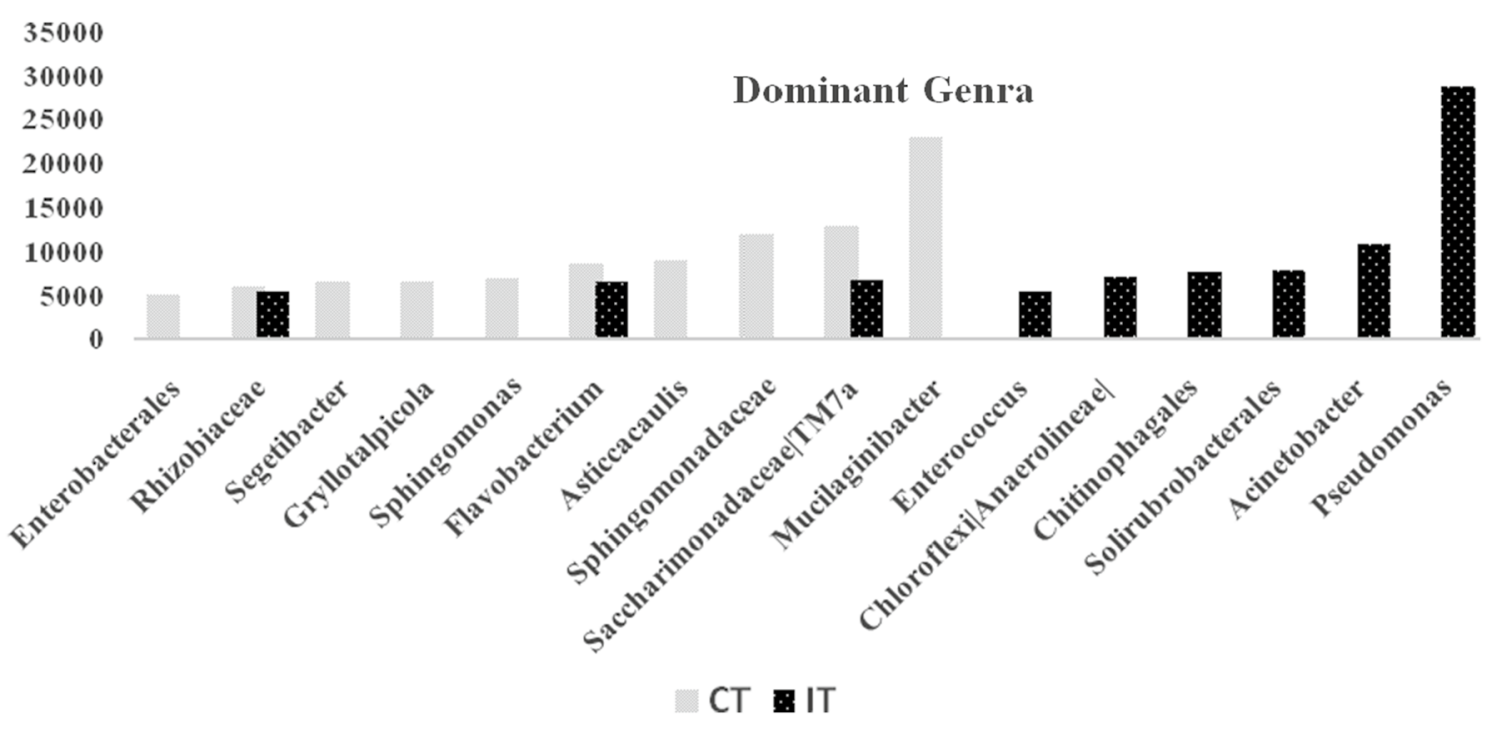

Fig. 5 Distribution and dominant genera in two different substrates (IT and CT)

A significant number of microbes are present in animals and plants' bodies, carrying out multiple interactions that can modulate the roles and behaviors within the complex. Like every other biological species, the microbial community is subject to succession. This study investigated the bacterial community in soil and tree trunk from healthy and diseased palm trees infected by Rhynchophorus ferrugineus (Red Palm Weevil) under field conditions. Till date there have been no reports on the microbial community structure RPW-infected palm trees. In our study, we found significant differences in the microbiological diversity of RPW-infected palm trees and healthy trees. Previous studies have shown that plant infection by pathogens has a profound effect on the microbial community of the plant host [26, 27]. The findings of this study, therefore, align with previously reported literature.

The microbial diversity was more prominently marked in tree trunks as compared to soil samples. In this analysis, soil samples were taken from the surface, partially explaining the lack of significant variations in diversity between soil from areas surrounding healthy and diseased trees. On the other hand, the difference in bacterial community diversity was significant in the trunk samples of diseased and healthy palm trees. Proença et al. [28], in their studies on pine wilt disease, found that infection can increase the diversity of endophytic wood-colonizing bacteria in the host $P$. pinaster trees. They also noticed that the endophytic bacterial community differed as the disease progressed, suggesting the importance of the host plant microbiome's disease progression development.

The time difference between the appearance of first symptoms after RPW infestation and the tree's death is crucial for the evolution of the bacterial community in the diseased tree. Considering the pathology of disease progression from initial latent infection followed by necrosis and finally death, it is imperative that different bacterial communities are involved in the various stages of the disease. However, in this study, samples were collected and analyzed from only one stage of the disease. Therefore, it is necessary to investigate the bacterial community at different stages of RPW infection and in the soil at different depths after disease occurrence.

Plants host individual and diverse microbial communities that are important for their survival, according to new evidence for their close relationship with their microbiota [29]. Understanding their relatedness using genome-based and high-throughput techniques remains highly pursued in microbiome research. In this study, we identified microbial communities at various taxonomic levels using the Illumina Seq technique. The soil microbiota is essential for suppressing soil-borne plant pathogens and improving the natural suppressiveness of soil. Microbiome disruption causes specific perturbation, which changes and shapes the network of soil microbial populations, increasing resistance to phytopathogens and diseases. Similar results were obtained in our study where bacterial population of the palm trees were same as that of the soil samples collected from the vicinity of the trees. Considering this, the ASVs were analyzed for the samples collected from the trunk since the difference in diversity in soil samples was not much marked in this study.

The number of phyla, families and genus was significantly high in infected tree trunk as compared to healthy tree trunk. In the case of phyla, Myxococcota, Acidobacteriota, and Firmicutes were exclusively detected in the diseased tree trunk. Members of these phyla have been recorded to be pathogenic in some cases. Among the families detected in 


\section{SOIL}

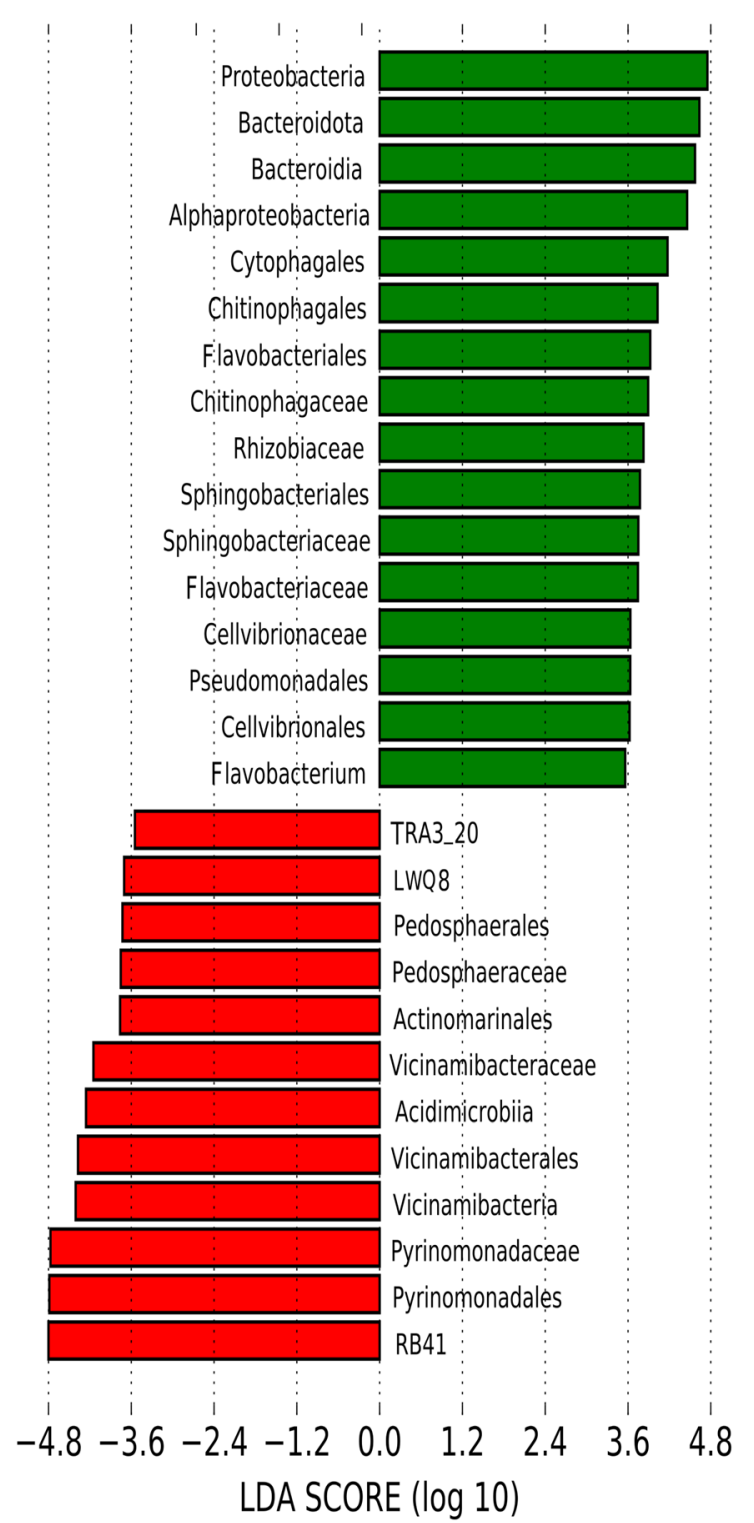

Fig. 6 Different types of cultures yielded from infected and healthy soil

diseased trunk samples, Pseudomonadaceae was the most dominant family, and this family accounted for $20 \%$ of the dominant families recorded in the tree trunk. Interestingly, a greater abundance of Pseudomonadaceae and Enterobacteraceae have been seen to be associated with dead trees, and these organisms are essential in biocontrol against pathogens in disease-suppressive soils [30].

In a study from gut microbiota from PRW, they identified Bacillus sp., Salmonella sp., Enterococcus sp. and Xanthomonas sp. [11], which was in concordance with our findings except for the finding of Salmonella sp. In another
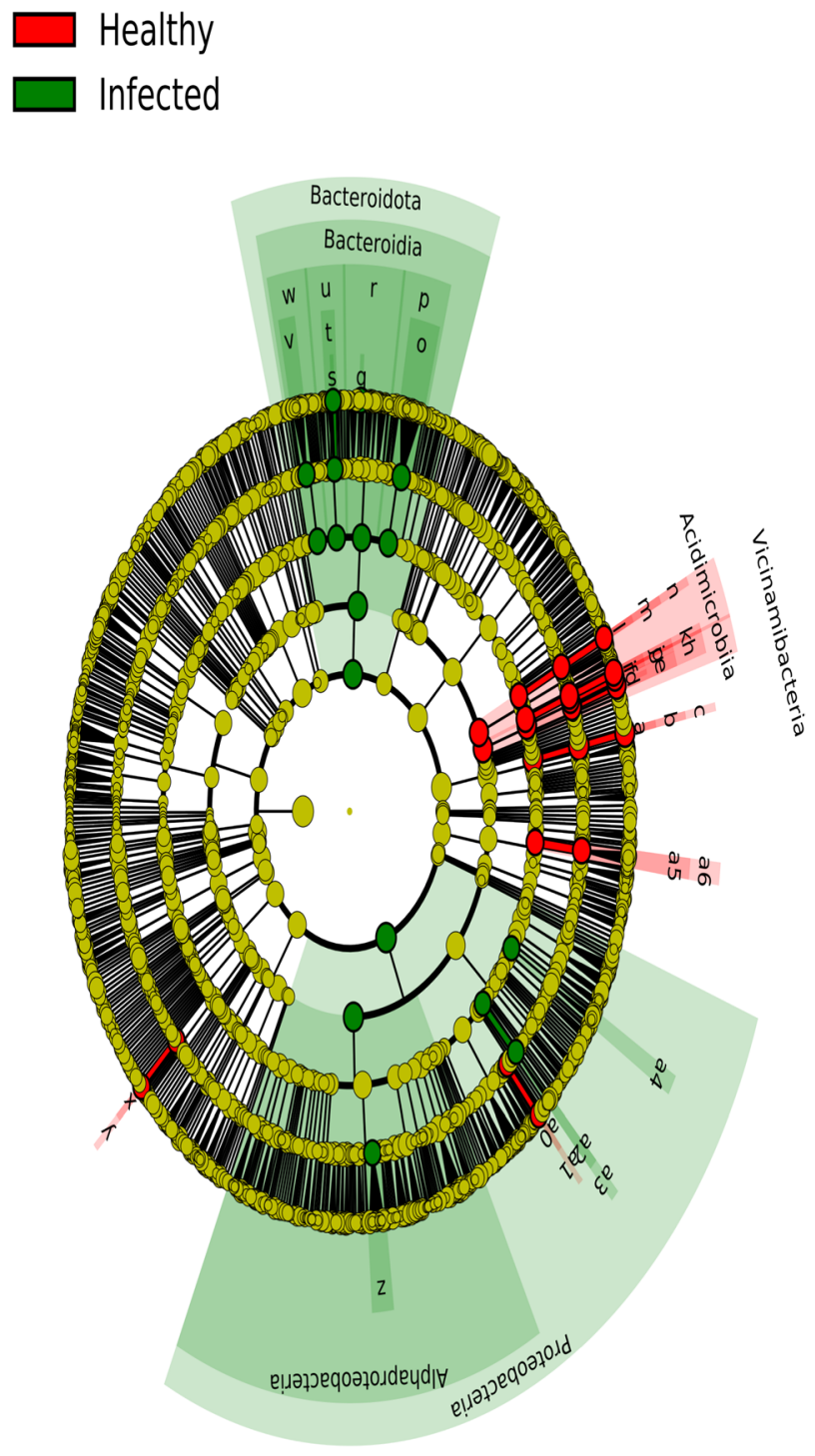

study, they identified Lactococcus lactis as the dominant species of the microbiota; however, in our study it was found, this might be because of that particular study deals with the gut isolates they could have isolated "Probiotic organism" [31].

Among the different genera, Caedibacteraceae (10\%) and Intrasporangiaceae were the most prominent, and these genera of bacteria have been previously reported to be associated with crop plants like sugarcane [32]. The composition of the bacterial community may strongly influence the establishment of antagonistic bacteria at appropriate times during 


\section{TRUNK}
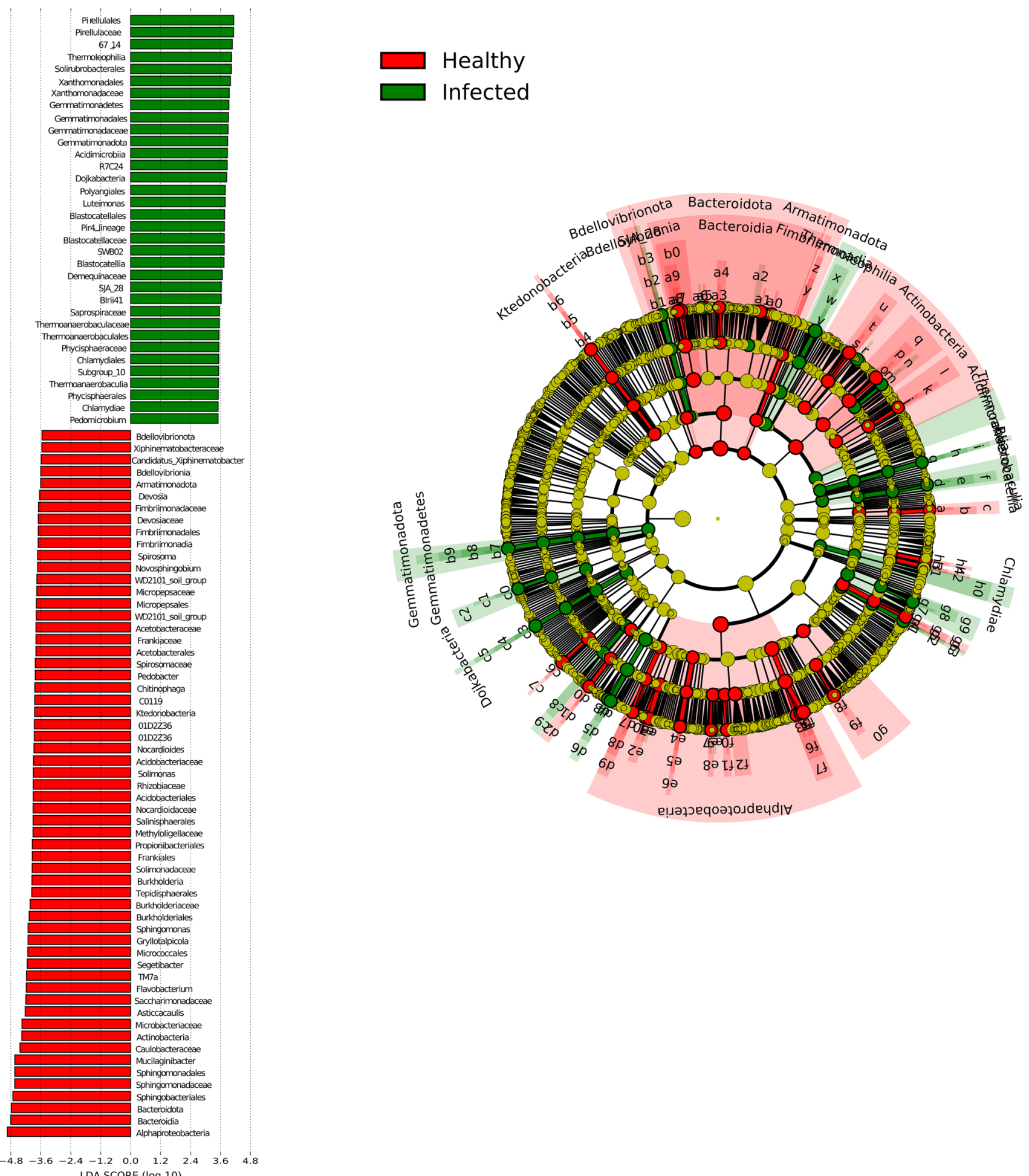

Fig. 7 Different types of culture yielded from the infected and healthy trunk 
plant development or the growing season. By understanding the variation and composition of the bacterial community of citrus, we can conduct RPW control treatments better and harness the plant's natural microbial population. This study will help to establish better management and treatment strategies.

\section{Conclusions}

Significant differences for the bacterial community structure and function between healthy and diseased trees were observed in trunk and soil samples of palm trees, suggesting that RPW can only affect the host bacteria community structure and function in certain anatomic regions of the host tree. Our study proved that taxonomic diversity variation was higher for infected tree trunk than the healthy tree trunk. Soil samples from the vicinity of healthy and infected trees did not have a significant variation in bacterial diversity, proving that changes in the microbial community are mostly present in the trunk regions. The bacterial community in the healthy trunk was dominated by Acidobacteria (phylum) and Mucilaginibacter (genus), whereas infected trunk, Proteobacteria (phylum), Firmicutes (phylum), and Pseudomonas (genus) were dominant. Further investigation of the host-microbial community and function in different stages of RPW and the rhizosphere is needed to elucidate the effect of RPW on the microbiome of palm trees. Our data suggest that not only gut microbes of RPW, other microbes commonly present on rhizosphere might contribute or augment the death of palm tree when it gets infected with the RPW. However further in vitro study is essential to prove the same.

Acknowledgements This study has been supported financially by the University of Ha'il, Project Number RG-191352. We are grateful to the University of Ha'il KSA for the financial support and the Ministry of Agriculture, Ha'il region, for technical assistance.

Open Access This article is licensed under a Creative Commons Attribution 4.0 International License, which permits use, sharing, adaptation, distribution and reproduction in any medium or format, as long as you give appropriate credit to the original author(s) and the source, provide a link to the Creative Commons licence, and indicate if changes were made. The images or other third party material in this article are included in the article's Creative Commons licence, unless indicated otherwise in a credit line to the material. If material is not included in the article's Creative Commons licence and your intended use is not permitted by statutory regulation or exceeds the permitted use, you will need to obtain permission directly from the copyright holder. To view a copy of this licence, visit http://creativecommons.org/licenses/by/4.0/.

\section{References}

1. Abbas, M.S.T.: IPM of the red palm weevil, Rhynchophorus ferrugineus. In: Ciancio, A.; Mukerji, K. (Eds.) Integrated Management of Arthropod Pests and Insect Borne Diseases. Integrated Management of Plant Pests and Diseases, Vol. 5. Springer, Dordrecht (2010). https://doi.org/10.1007/978-90-481-8606-8_9

2. Al-shawaf, A.M.; Al-abdan, S.; Al-abbad, A.H.; Ben Abdallah, A.; Faleiro, J.R.: Validating area-wide management of Rhynchophorus ferrugineus (Coleoptera: Curculionidae) in date plantation of Al-Hassa. Indian J. Plant Prot. 40(4), 255-259 (2012)

3. Barranco, P.: De La Pena J El picudo de laspalmeras, Rhynchophorus ferrugineus, nuevaplagas en Europa. Phytoma-Espana 67, 36-40 (1996)

4. Abraham, V.; Shuaibi, M.A.A.; Faleiro, J.; Abozuhairah, R.A.; Vidyasagar, P.: An integrated management approach for red palm weevil Rhynchophorus ferrugineus Oliv. akey pest of date palm in the Middle East. J. Agri. Marine Sci. 3(1), 77-83 (1998). https:// doi.org/10.24200/10.24200/jams

5. Llácer, E.; Negre, M.; Jacas, J.A.: Evaluation of an oil dispersion formulation of imidacloprid as a drench against Rhynchophorus ferrugineus (Coleoptera, Curculionidae) in young palm trees. Pest. Manag. Sci. 68, 878-882 (2012). https://doi.org/10.1002/ps.324

6. Mazza, G.; Francardi, V.; Benvenuti, C.; Cervo, R.; Faleiro, J.R.; et al:: An overview on the natural enemies of Rhynchophorus palm weevils, with focus on $R$. ferrugineus. Biol. Control 77, 83-92 (2014)

7. Crowder, D.W.; Northfield, T.D.; Strand, M.R.; Snyder, W.E.: Organic agriculture promotes evenness and natural pest control. Nature 466(7302), 109-112 (2010). https://doi.org/10.1038/natur e09183

8. Bale, J.S.; van Lenteren, J.C.; Bigler, F.: Biological control and sustainable food production. Philos. Trans. R. Soc. Lond. B Biol. Sci. 363(1492), 761-776 (2008). https://doi.org/10.1098/rstb. 2007.2182

9. Nardon, P.; Lefevre, C.; Delobel, B.; Charles, H.; Heddi, A.: Occurrence of endosymbiosis in Dryophthoridae weevils: cytological insights into bacterial symbiotic structures. Symbiosis 33, 227-241 (2002)

10. Concord, C.; Despres, L.; Vallier, A.; Balmand, S.; Miquel, C.; et al.: Long-term evolutionary stability of bacterial endosymbiosis in Curculionoidea: additional evidence of symbiont replacement in the Dryophthoridae family. Mol. Biol. Evol. 5, 859-868 (2008). https://doi.org/10.1093/molbev/msn027

11. Khiyami, M.; Alyamani, E.: Aerobic and facultative anaerobic bacteria from gut of red palm weevil (Rhynchophorus ferrugineus). Afr. J. Biotechnol. 7, 1432-1437 (2008)

12. Tagliavia, M.; Messina, E.; Manachini, B.; Cappello, S.; Quatrini, P.: The gut microbiota of larvae of Rhynchophorus ferrugineus Oliver (Coleoptera: Curculionidae). BMC Microb. 14, 136 (2014)

13. Valzano, M.; Achille, G.; Burzacca, F.; Ricci, I.; Damiani, C.; et al.: Deciphering microbiota associated to Rhynchophorus ferrugineus in Italian samples: a preliminary study. J. Entomol. Acarol. Res. 44, e16 (2012)

14. Butera, G.; Ferraro, C.; Corazza, S.; Alonzo, G.; Quatrini, P.: The culturable bacterial community of frass produced by larvae of Rhynchophorus ferrugineus Olivier (Coleoptera: Curculionidae) in the Canary island date palm. Lett. Appl. Microbiol. 54, 530536 (2012). https://doi.org/10.1111/j.1472-765X.2012.03238.x

15. Pu, Y.C.; Ma, T.L.; Hou, Y.M.; Sun, M.: An entomopathogenic bacterium strain, Bacillus thuringiensis, as a biological control agent against the red palm weevil, Rhynchophorus ferrugineus (Coleoptera: Curculionidae). Pest Manag. Sci. 73(7), 1494-1502 (2017) 
16. Alanazi, N.A.; Sulieman, A.M.; Alshammari, N.I.; Al-Azmi, M.; Aziz, A.; Elbadri, G.A.; Stephenson, S.L.: Fungi related with the red palm weevil (Rhynchophorus ferrugineus) in the Hail Area, Northern Saudi Arabia. Biosci. Biotech. Res. Commun. 13(4), 2233-2239 (2020). https://doi.org/10.21786/bbrc/13.4/91

17. Mohamed, A.M.; Farooq, M.; Pathak, M.R.: Identification and characterization of bacterial community associated with the chewed feeding waste of red palm weevil in infested date palm trees. Adv. Biosci. Biotechnol. 11(3), 80-93 (2020). https://doi. org/10.4236/abb.2020.113007

18. Maejima, K.; Oshima, K.; Namba, S.: Exploring the phytoplasmas, plant pathogenic bacteria. J. Gen. Plant. Pathol. 80, 210-221 (2014). https://doi.org/10.1007/s10327-014-0512-8

19. Romanazzi, G.; Musetti, R.; Marzachì, C.; Casati, P.: Induction of resistance in the control of phytoplasma diseases. Petria 19, 113-129 (2008)

20. Saracco, P.; Marzachì, C.; Bosco, D.: Activity of some insecticides in preventing transmission of chrysanthemum yellows phytoplasma 'Candidatus phytoplasmaasteris' by the leafhopper Macrosteles quadripunctulatus Kirschbaum. Crop Prot. 2009(27), 130-136 (2008)

21. Al Othaim, A.; Marasini, D.; Carbonero, F.: Impact of increasing concentration of tart and sweet cherries juices concentrates on healthy mice gut microbiota. Food Front. 1(3), 224-233 (2020)

22. Kozich, J.J.; Westcott, S.L.; Baxter, N.T.; Highlander, S.L.; Schloss, P.D.: Development of a dual-index sequencing strategy and curation pipeline for analyzing amplicon sequence data on the MiSeq Illumina sequencing platform. App. Environ. Microbiol. 79(17), 5112-5120 (2013). https://doi.org/10.1128/AEM. 01043-13

23. Habineza, P.; Muhammad, A.; Ji, T.; Xiao, R.; Yin, X.; Hou, Y.; Shi, Z.: The promoting effect of gut microbiota on growth and development of red palm weevil, Rhynchophorus ferrugineus (Olivier)(Coleoptera: Dryophthoridae) by modulating its nutritional metabolism. Front. Microbiol. 29(10), 1212 (2019)

24. Tagliavia, M.; Messina, E.; Manachini, B.; Cappello, S.; Quatrini, P.: The gut microbiota of larvae of Rhynchophorus ferrugineus
Oliver (Coleoptera: Curculionidae). BMC Microbiol. 14(1), 1-1 (2014)

25. Muhammad, A.; Fang, Y.; Hou, Y.; Shi, Z.: The gut entomotype of red palm weevil Rhynchophorus ferrugineus Olivier (Coleoptera: Dryophthoridae) and their effect on host nutrition metabolism. Front. Microbiol. 8, 2291 (2017)

26. Hammer, O.; Harper, D.A.T.; Ryan, P.D.: PAST: paleontological statistics software package for education and data analysis. Palaeontol. Electron. 4(1), 1-9 (2001)

27. Douala-Meli, C.; Langer, E.; Mouafo, F.T.: Fungal endophyte diversity and community patterns in healthy and yellowing leaves of Citrus limon. Fungal. Ecol. 6, 212-222 (2013)

28. Tian, B.Y.; Cao, Y.; Zhang, K.Q.: Metagenomic insights into communities, functions of endophytes, and their associates with infection by root-knot nematode, Meloidogyne incognita, in tomato roots. Sci. Rep. 5, 17087 (2015)

29. Proença, D.N.; Francisco, R.; Kubik, S.; Schöler, A.; Vestergaard, G.; Schloter, M.; Morais, P.V.: The microbiome of endophytic, wood colonizing bacteria from pine trees as affected by pine wilt disease. Sci. Rep. 7, 1-9 (2017)

30. Lalande, B.M.; Hanna, J.W.; Wardwell, M.; Kim, M.S.; Klopfenstein, N.B.; Stewart, J.E.: Assessing soil microbial communities associated with tree health in a western white pine (Pinusmonticola) stand. In: Proceedings of the 66th Western International Forest Disease Work Conference, pp. 27-30 (2019)

31. Jia, S.; Zhang, X.; Zhang, G.; Yin, A.; Zhang, S.; Li, F.; Wang, L.; Zhao, D.; Yun, Q.; Wang, J.; Sun, G.: Seasonally variable intestinal metagenomes of the red palm weevil (Rhynchophorus ferrugineus). Environ. Microbiol. 15(11), 3020-3029 (2013)

32. Dong, M.; Yang, Z.; Cheng, G.; Peng, L.; Xu, Q.; Xu, J.: Diversity of the bacterial microbiome in the roots of four saccharum species: S. spontaneum, S. robustum, S. Barberi, and S. officinarum. Front. Microbiol. 9, 267 (2018). https://doi.org/10.3389/fmicb. 2018.00267 